\title{
The Entrepreneurship Exploration Based on The Platform of QQ \& WeiChat Cloud Printing +
}

\author{
Zhu Yanping, Gong Xuhao, Shi Tao
}

School of Electronic and Information Engineering, Nanjing University of Information Science and Technology, Nanjing, China

\section{Email address:}

zhuyanping321@163.com (Zhu Yanping)

\section{To cite this article:}

Zhu Yanping, Gong Xuhao, Shi Tao. The Entrepreneurship Exploration Based on The Platform of QQ \& WeiChat Cloud Printing +. Science Innovation. Vol. 6, No. 1, 2018, pp. 24-27. doi: 10.11648/j.si.20180601.16

Received: January 4, 2018; Accepted: March 5, 2018; Published: March 9, 2018

\begin{abstract}
Under the background of Internet + background, college students' self-employment and flexible employment model have been widely supported and helped by the society, which has become an effective way to alleviate employment. This project is based on the "QQ \& WeChat Cloud Printing +" platform, which is combined with professional expertise, through the cooperation and communication between the team members, undergo the project analysis, research and implement, has realized the preliminary entrepreneurship and reached the expected operating effect. The project can effectively motivate college students to combine their interests and talents to start their own businesses, and stimulate innovative thinking ability and improve students' employ ability.
\end{abstract}

Keywords: Internet +, Entrepreneurship, Teaching Practice, Innovate

\section{“基于Q信平台云印+”的创业探索}

\section{朱艳萍, 巩叙皓, 史涛}

南京信息工程大学, 电子与信息工程学院, 南京, 中国

\section{邮箱}

zhuyanping321@163. com（朱艳萍）

摘要: 在互联网+背景之下, 大学生自主创业和灵活的就业模式得到了社会的广大支持和帮助, 成为缓解就业的一种有 效途径。本项目以 “基于 $Q$ 信平台云印+” 为基础, 结合专业特长, 通过团队成员间的合作交流, 经过项目分析、调研 和实施, 实现了初步的创业, 达到了预期的运营效果。该项目能够有效地激励大学生结合自身兴趣、特长开展创业, 并激发创新思维能力，提高学生就业能力。

关键词: 互联网+, 创业, 教学实践, 创新

\section{1. 引言}

创新创业是指基于技术、产品、品牌、服务、商业模 式、管理、组织、市场、渠道等方面的某一点或几点创新 而进行的创业活动。目前, 中国高校面临的毕业生就业问 题日益凸显, 企业对创新型人才的渴求使高校向创新创业
教育的转变成为一种必然。因此, 创新创业教育也成为中 国高等教育改革的必然趋势、培养目标和高校未来发展方 向 [1]。

根据现有相关研究, 中国印刷产业的规模每年有一万 亿元, 但行业利润空间逐年压缩, 移动互联网的普及和物 联网的来势汹汹 [2], 让印刷业看到了希望, 构建起了这 个行业革命性 “超级快印” 的商业模式 [3]; 相对于美国 
来说 [4], 目前数字印刷和网络印刷在中国还很不普及, 数字印刷业务资源虽然丰富, 但数字印刷产业发展稍显滞 后, 随着互联网在中国的迅速发展, 中国印刷行业的商业 模式将逐步朝着 “印刷电商+连锁快印 + 智能印厂+区域物 流”的智能高效方向发展 $[5]$; 张育林等人 [6]在以”共云、 共印、共营、共赢”的2017首届中国云印刷高峰论坛”表示, 以产品为出发点, 用创意的力量寻求转型突破 [7]。

在研究方法上, 学生亲身调查市场行情深入分析校园 需求。现行市场创新的云印平台有随米、片客、海天等, 但是每一种平台的背后都暗藏次级创业者巨大的利润损 失, 并不适合在校学生; 自助文印系统是智慧图书馆项目 中的关键组成, 能够实现全程自助无人化管理, 但是机器 本身并不能为客户检查文档, 而且普及率不高、打印纸页 数受限, 与到店打印并无太大区别; 云印刷虽然高效便宜, 但并不适用于校园零散市场。

校园用户对于校园云打印服务在效率、信用安全和 社交方面有一定的需求, 同时在打印资料交付、复习资料 库和校内外打印资源等多方面存在共享资源的可能性 [8]。至2017年8月中国互联网用户即时通讯使用率为 96. 30\% [9]，为云印提供了极便捷的网络平台，“基于 $Q$ 信平台云印 + ”服务针对校园需求以 $\mathrm{QQ}$ 、微信两大社交平 台为基础进行业务往来, 改变市场目前存在的店面打印 方式及基于现代通讯、计算机、印刷技术、物流体系建 立起来的远程网络印刷服务, 实现基于 $5 \mathrm{P} 4 \mathrm{~F}$ 的电子商务 模式 [10], 促进校园文档安全、资料共享及社交网的扩 大，体现了人文服务的巨大优势。通过团队前期基础网 络打印业务发展, 为中后期开发衍生业务、创建专属网 站及校园网云柜建设积累资金, 逐步形成稳步盈利、方 便同学的高效商业模式。

\section{2. 市场调研}

\section{1. 调研基本情况}

此次调研主要针对南京信息工程大学学生学习期间 的打印需求情况, 以本校师生作为调查对象进行随机调 研。实施调研人员 5 人, 调研内容涉及: 打印、复印、扫 描及印刷照片等基础业务, 不同业务的价格区间和对速 印行业的期许等方面的信息。采用的调查方法包括：问 卷调查法、直接访谈法、网络调查法和二手数据分析等 方法 [11]。数据的录入处理采用Exce1。此次调研历时 10 天, 共分为三个阶段: 第一阶段, 调研内容的确定、问 卷的设计等准备性工作。第二阶段, 主要工作内容包括 对调查范围内的学生进行专访和问卷调查。第三阶段, 包括数据的录入处理, 撰写调研报告等工作 [12]。截止 调研工作结束, 本次调研随机抽取 200 名学生进行调查, 实际发放问卷 91 份, 网络调查 59 份, 直接访谈 50 人, 收 回有效问卷 133 份。

\section{2. 调研结果分析}

通过对问卷调查数据的整理, 我们了解到市场现阶段 的打印价格大同小异差距不大，而且学生对打印价格并不 会在意太多, 反而对于服务的品种与质量有着莫大期许, 比如: 送资料到宿舍教学楼、云柜自取、前辈互动、学习 交流、资源共享 $[13]$ 等。

\section{3. 业务简介}

根据前期的调研结果分析, 经团队慎重考虑, 拟采用 自主式创业 [14]模式, 针对技术服务进行业务开发。主要 包括以下内容:

\section{1. 专业跟踪反馈}

根据院校开设专业及课程, 以学年为周期, 对高年级 及毕业生访问经验, 对低年级及时反馈, 为低年级学生提 供生涯规划指导, 促进高低年级间的学习感情交流, 扩大 交际圈。

\section{2 . 资料整理共享}

根据反馈情况, 定向总结学习资料并共享 [15], 以良 好为底线, 向满分冲刺。减少学生不必要的时间浪费, 更 好地发展个人规划。

\section{3. 职业技能培训}

此项业务针对那些到大四还没有目标没有规划的学 生, 根据社会就业市场及个人兴趣定向培训就业技能, 满 足企业人才需求 $[16]$ 。

\section{4. 辅导班代理推广}

通过对各大辅导机构的切身走访调查, 选出可信可靠 的有利于学生生涯发展的机构进行代理推广, 为同学的发 展添砖加瓦, 排忧解难。

\section{5. 设备租侦}

针对那些短期需要大批量印购而需低成本的班级或 机构, 为他们提供硬件技术支持 [17]。

\section{6. 基础图文业务整合}

通过 $\mathrm{Q}$ 信平台整合周边资源 [18] 为学生提供便捷基础 的图文印制服务。

\section{4. 运营概况}

\section{1. 启动资金来源}

学院品牌专业资助 6000 元, 团队筹集 2000 元, 指导老 师资助 2000 元。 


\section{2. 硬件购置}

表1 硬件购置清单及价格。

\begin{tabular}{lllllll}
\hline 项目 & 佳能IP2780 & 佳能G3800 & HL-5440D & 施乐M115B & 耗材总汇 & 总计 \\
\hline 单价 $(R M B)$ & 358 & 1428 & 1960 & 818 & 2317 & 6881 \\
\hline
\end{tabular}

\section{3. 运营策略}

\section{3. 1. 市场推广}

A. 在大学园区进行宣传时, 加强与学校各院系、各 社团、各班级之间的合作，争取得到学校更多方面的支持 及与各学院各班级之间更多的业务合作机会。

B. 在微信、QQ等社交软件上发起集赞活动，根据集 赞数量分阶段奖励各类奖品。

\section{3. 2. 市场营销}

A. 采用会员制度，提高顾客忠诚度 [19]，吸收市场 资金, 二次发展。

B. 价格策略 [20], 适时调整价格水平以绝对的价格 优势及服务质量占领市场。

\section{5. 财务分析}

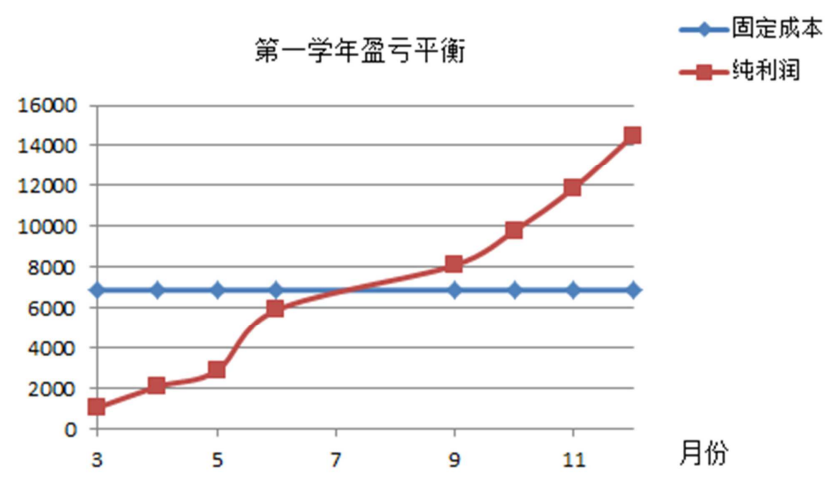

图1 第一学年财务盈亏状况。

根据实际运行情况的财务分析，团队在 9 月份实现完 全营利; 学年的打印高峰期集中在每学期的期末前一个月 及毕业季, 这个阶段的耗材成本会小幅提升, 所以应在每 个学期开始根据预算大批采购原料, 适时调整价格策略。

\section{6. 项目前景}

本Q信打印平台基础业务定位于校园, 满足学生实时、 大量的打印需求, 解决用户在打印时遇到的诸多问题, 提 高了打印行业的便捷性。我们的平台网站可以自己设计, 而且由于专业优势, 硬件系统坏了也可以自己简单维修等, 所以有效降低了开发的成本; 采用的策略是定位于校园, 这种策略的运用, 使得市场竞争阻力、成本等降低, 便于 平台的运用和推广。各项业务齐头并进，符合校园市场需 求, 利于有效快速占据行业市场。近一年的试运行期间, 合作机构与班级的数量都在成比例增加, 且积累了较好的
口碑, 很多潜在客户都是老客户推荐而来, 因此项目的未 来前景可观，有很大的在发展空间。

\section{7. 结论}

大学生是最具创新、创业潜力的群体之一, 在高等学 校开展创新创业教育, 积极鼓励高校学生自主创业, 是教 育系统深入学习实践科学发展观, 服务于创新型国家建设 的重大战略举措; 是深化高等教育教学改革, 培养学生创 新精神和实践能力的重要途径; 是落实以创业带动就业, 促进高校毕业生充分就业的重要措施 [21]。

面对严酷的就业环境, 创新创业不仅是组织教学中不 能缺少的部分, 也是每位大学生所应必备的能力。在院校 的各方面支持之下, 本项目平台成功运营, 大大提升了学 生的学业水平和专业水平, 实现了学业和创业、市场和专 业、理论和实践的结合, 给予了学生对创业过程所遭遇的 各种难题的处理以丰富经验, 增强了其吃苦耐劳、抗挫折 的能力 [22]。可以为后续开展学生创新创业活动提供一定 的参考和借鉴。

\section{致谢}

感谢 “江苏省高校品牌专业建设工程资助项目” 以及 南京信息工程大学 “大学生实践创新训练计划项目: 201610300245”对本文创新课题的大力资助。

\section{参考文献}

[1] 葛秀丽, 高爽. 探寻创新创业活动对大学生创新创业能力的 培养 [J]. 青年文学家, 2013， 12: 80.

[2] 曹祎遐, 何塑. 新制造时代下的工业互联网 [J]. 上海信息化, 2017, (1): 17-20.

[3] Print Applications: Revenues, Processes and Run Lengths In Commercial Printing [J]. Printing impressions, 2015, (10).

[4] Nick Kleanthous. How to Win More than Just Print Business [J]. Printing industries of America:the magazine, 2015, (1).

[5] 董祖明. 天意有福的“互联网+数字印刷”实践 $[J]$. 印刷志, 2017, 11: 28-31.

[6] 2017首届中国云印刷高峰论坛 共云、共印、共营、共赢 [J]. 数字印刷, 2017, (1) : 66-67。

[7] Tan, Teri. Retooling the Hong Kong \& China print business: print suppliers are planning aggressive moves and extensive solutions to meet evolving publishing needs and challenges [J]. Publishers Weekly, August 28, 2017. 
[8]毛伟. 我国互联网发展现状 [J]. 中国科学院, 2008 (1): 4-9。

[9] 智研咨询集团. 《2017-2022年中国通信市场供需预测及发 展趋势研究报告》 [EB/OL]. http://www. chyxx. com/industry/201708/549122. html, 2017年8月9号。

[10] 方孜, 王刊良. 电子商务模式分析与方法创新 [J]. 西安交通 大学学报（社会科学版），2002，22(2)：65-69。

[11] 肖梁, 董亚妮. 市场调研策划 [M]. 成都: 西南财经大学出版 社，2010年4月。

[12] 李晔, 刘华山. 问卷调查过程中的常见问题与解决方法 [J]. 教育研究与实验, 2006, (2) : 61-64。

[13] 黄有福. 高校优质教学资源共享的意义和策略探索 $[\mathrm{J}]$. 经 济视角（下），2011，(4)：57-59。

[14] 黄建桥, 黄炜, 程钰, 等. “互联网+” 大学生创业模式的 评价研究 $[J]$. 湖北农科学, 2017, 56 (1)：181-186。

[15] 杨丰梅, 王安瑛, 吴军, 等. 电商平台信用信息共享策略演 化 $[J]$. 系统工程学报, 2017, 32 (5) : 596-693。
[16] 代学钢, 贾会棉. 企业人才需求及职业技能培训情况实证研 究——以河北省中小企业为例 $[J]$. 产业与科技论坛, 2011, 10 (19)：108-110。

[17] 刘国强, 史胜男, 薛永福, 等. “自助打印机” 打印设备研 究 $[J]$. 电脑知识与技术, $2017,13(27)$ ：215-216。

[18] 易朝辉. 资源整合能力、创业导向与创业绩效的关系研究 $[J]$. 科学学研究, 2010, 28(5):757-762。

[19] 缪仁杰. 电子商务环境下顾客忠诚度的培养 [J]. 企业导报, 2016, 7:121。

[20] 曹曼青, 李亮. 市场营销中价格策略问题的思考 $[\mathrm{J}]$. 市场周 刊（理论研究），2009，(6)：61-63。

[21] 中华人民共和国教育部. 教育部关于大力推进高等学校创 新创业教育和大学生自主创业工作的意见 [Z]. 2010年5月4 日。

[22] 谭杉. 当今在校大学生创业特点研究 [J]. 华章, 2013, 4: 119 。 